\title{
Twelve wise men at the Vatican
}

\author{
from J.M. Lowenstein
}

A RECENT meeting* of twelve scholars at the Pontifical Academy of Sciences in the Vatican Gardens proved historic in two respects. First, the group, which consisted of palaeontologists; geneticists and molecular biologists and which had been specifically assembled to reconcile the palaeontological evidence of primate evolution with that from molecular biology, was able to agree on a scenario for primate evolution over the past 30 million years. To many protagonists of the two disciplines this will seem something of a miracle. Second, the highest scientific body of the Catholic Church produced a strong statement supporting the evolutionary hypothesis as the explanation for the origin and diversity of living primates - just a few weeks after the hundredth anniversary of Darwin's death.

Presiding over the working group was the President of the Pontifical Academy, Carlos Chagas, a neurophysiologist from Brazil and scientific adviser to Pope John Paul II. The pope reportedly takes a keen interest in the activities of the Academy.

Palaeontologists and molecular biologists have been divided over whether the various living apes and man diverged early on (20 Myr BP) or late (5-7 Myr BP). Some fossil evidence, particularly the dating of Ramapithecus, considered by many palaeoanthropologists to be hominid, supports the earlier date. A mass of biochemical data showing about 99 per cent identity between the DNA and proteins of chimpanzee, gorilla and man implies, from inferred rates of DNA and protein change, that the separation occurred at the later date.

The working group was able to reconcile the fossil and biochemical evidence by taking into account evidence that Ramapithecus is not hominid but is more probably related (along with Sivapithecus) to the orang-utan lineage. Particularly important are the recent discovery of a Sivapithecus face which has many orang-

- Participants at the conference, held 24-27 May 1982, were E Bone (Belgium), Y. Coppens and J. Lejeune (France), R. Doolittle, L. Greenfield, J. Lowenstein, D. Pilbeam and E. Simons (USA), C. Pavan (Brazil), G. Sermonti (Italy) and P. Tobias (S. Africa) utan-like features (see Pilbeam Nature 295, 232; Andrews News and Views 295, 185; 1982) and the finding that limb bones attributed to Ramapithecus or Sivapithecus (but not found in association with jaws and teeth) strongly suggest an arboreal adaptation. Supporting evidence comes from a new radioimmunoassay technique. Preliminary results (Lowenstein) show the fossil proteins of Ramapithecus/Sivapithecus to be most like the serum proteins of orang-utan, gibbon and gorilla, less like those of man and chimpanzee and least like those of monkey and other mammals - suggesting the Miocene genera Ramapithecus/Sivapithecus were hominoid (ancestral to apes or to apes and humans) rather than hominid.

The first true hominids were agreed to be the australopithecines of East and South Africa, dated from about $4 \mathrm{Myr}$ BP. Coppens, who with Johanson and White named the species Australopithecus afarensis, now considers that the observed large variation in size may not be due to sexual dimorphism as previously thought, but may indicate that more than one species was present at that early time. In the period between 4 and $14 \mathrm{Myr}$, when the common ancestor of man, chimpanzee and gorilla probably lived, there is no significant African fossil record of hominids or hominoids and no fossil record at all for chimpanzee and gorillas. Fossils from this period are badly needed to decide the path of human evolution.

The earliest record of monkey-like and ape-like primates, known from the Fayum formation of Egypt, was reviewed by Simons, who also described a new genus, Qatrania. Aegyptopithecus, earlier discovered in the Fayum by Simons, has teeth resembling those of apes but limb bones resembling those of New World howling monkeys. Aegyptopithecus, dated at 25-35 Myr, may be ancestral either to Old World monkeys and hominoids or to hominoids only, depending on the dating of the monkey-hominoid split. Molecular data suggest the split occurred 20-25 Myr BP which would make Aegyptopithecus ancestral to both groups. Palaeoanthropologists commonly date the split much earlier, so that in their view, Aegyptopithecus is a hominoid ancestor only. Here, as in so much of primate evolution, accurate dating of divergences between lineages becomes critical.

One characteristic proposed as evidence of a phylogenetic relationship between Ramapithecus and Australopithecus is the presence of thickly enamelled molars. In Greenfield's opinion, this trait has very limited phylogenetic significance and does not support the inferred relationship. Rather, bipedalism and not small canines or an enlarged brain appears to be the emergent hominid trait - although what ecological conditions encouraged bipedalism is not at all clear.

Molecular biology can be expected to prove of increasing value in providing information about the relationships of extant higher primates. Doolittle pointed out that the study of pseudogenes, which change rapidly without any apparent selection pressures to restrict base pair substitutions, may provide particularly useful data.

Many other controversial areas of primate evolution were discussed. Tobias put forward the view that Homo habilis may have been capable of speech (albeit rudimentary) on the basis of an inferred well-developed vocal tract, endocast evidence of possible Broca's and Wernicke's areas, and a stone tool technology reflecting learned technical skills requiring speech for their transmission.

Overall, though, the working group was able to agree on its conclusion:

"We freely acknowledge that there is room for differences of opinion on such problems as species formation and the mechanisms of evolutionary change. Nonetheless, we are convinced that masses of evidence render the application of the concept of evolution to man and other primates beyond serious dispute".

J. M. Lowenstein is Clinical Professor of Medicine at the University of California, San Francisco, California 94143. 